\title{
Publisher's Note: Defining the free-energy landscape of curvature-inducing proteins on membrane bilayers [Phys. Rev. E 90, 022717 (2014)]
}

Richard W. Tourdot, N. Ramakrishnan, and Ravi Radhakrishnan (Received 22 April 2016; published 28 April 2016)

DOI: 10.1103/PhysRevE.93.049909

This paper was published online on 25 August 2014 with an error in Eq. (23).

Equation (23) should read as

$$
\langle\mathcal{H}\rangle=\frac{1}{2 A_{P}} \sum_{\vec{q}} \sum_{\overrightarrow{q^{\prime}}}\left\{\left[q^{2} q^{\prime 2}\left\langle h_{q} h_{q^{\prime}}\right\rangle+q^{2}\left\langle h_{q} h_{0, q^{\prime}}\right\rangle+q^{\prime 2}\left\langle h_{0, q} h_{q^{\prime}}\right\rangle+\left\langle h_{0, q} h_{0, q^{\prime}}\right\rangle\right] \kappa_{q+q^{\prime}}+q q^{\prime}\left[\left\langle h_{q} h_{q^{\prime}}\right\rangle\right] \sigma_{q+q^{\prime}}\right\}
$$

The equation has been corrected as of 22 April 2016. The equation is incorrect in the printed version of the journal. 